\title{
Analisis Sanitasi Sekolah Dasar Negeri dan Swasta di Kecamatan Medan Tuntungan Tahun 2016
}

\author{
Sanitation Analysis of Public and Private Primary Schools in Medan \\ Tuntungan Subdistrict in 2016
}

\author{
Kharis Meiwan K.Tel* ${ }^{*}$, Evawani M. Silitonga ${ }^{2}$ \\ ${ }^{1,2}$ Program Studi S1-Kesehatan Masyarakat, Sekolah Tinggi Ilmu Kesehatan Sumatera Utara \\ *Korespondensi Penulis: eva_rosdiana@uui.ac.id
}

\begin{abstract}
Abstrak
Sanitasi lingkungan sekolah sebagai bagian dari prasarana pendidikan cenderung dilupakan keberadaannya. Padahal kondisi sanitasi yang buruk dapat memberi pengaruh negatif terhadap tingkat kesehatan peserta didik sekolah yang bersangkutan. Sanitasi lingkungan merupakan aktivitas yang diarahkan untuk meningkatkan dan mempertahankan standar kondisi lingkungan yang mendasar, seperti hal tersebut mempengaruhi kesejahteraan manusia. Tujuan penelitian ini untuk melihat Sanitasi Sekolah Dasar Negeri dan Swasta di Kecamatan Medan Tuntungan. Sampel dalam penelitian ini terdiri dari 5 SD Negeri dan 5 SD Swasta diKecamatan Medan Tuntungan. Pengumpulan data primer dilakukan dengan wawancara langsung dan observasi menggunakan ceklist dan data sekunder diperoleh dari kantor camat dan BPS. Penelitian ini bersifat deskriptif dimana menggambarkan Sanitasi Sekolah Dasar Negeri dan Swasta di Kecamatan Medan Tuntungan. Berdasarkan Hasil Penelitian menunjukan bahwa Sanitasi Sekolah Dasar Negeri dan Swasta yang Masuk dalam Kategori Sehat adalah SDN-1, SDS-1, SDS-2, SDN-2 dan SDS-3 dimana Total Penilaian Keseluruhan diatas 1.695-2.600. Sedangkan 5 SD lainya Negeri maupun Swasta termasuk Kategori Tidak Sehat. Pihak sekolah yang belum memenuhi syarat pada tiap-tiap variabel seperti Sarana Jamban menyediakan Tempat Cuci tangan Umum, Bak Air pada WC/KM yang bersih dan Alat bahan pembersih Kamar Mandi, kemudian Sarana Pembuangan Sampah diletakan pada tempat yang aman dan bersih serta TPS nya jauh dari lingkungan sekolah, dan sarana pembuangan air limbah dibuat dengan system tertutup dan kedap air dan diharapkan Sarana Kualitas Fisik Bangunan terutama kepadatan Kelasnya maksimal 28-32 orang/kelas agar kelas tidak terlalu padat.
\end{abstract}

Kata Kunci : Sanitasi Sekolah Dasar

\begin{abstract}
Sanitation of the school environment as part of educational infrastructure tends to be forgotten. Even though poor sanitation conditions can have a negative influence on the health level of the school students concerned. Environmental sanitation is an activity that is directed at improving and maintaining basic environmental conditions, as it affects human well-being. The purpose of this study was to look at the Public and Private Elementary School Sanitation in Medan Tuntungan District. The sample in this study consisted of 5 Public Elementary Schools and 5 Private Elementary Schools in Medan Tuntungan District. Primary data
\end{abstract}


collection is done by direct interviews and observations using checklists and secondary data obtained from the sub-district office and BPS. This research is descriptive in nature which describes the Sanitation of Public and Private Elementary Schools in Medan Tuntungan District. Based on the results of the study, the Sanitation of Public and Private Elementary Schools Included in the Health Category were SDN 067247, SDS Bharlind School, SDS Catholic Budi Murni-2, SDN 068003 and SDS Elida where the Overall Total Assessment was above 1,695-2,600. Whereas the other 5 elementary schools, both public and private, are categorized as Unhealthy Schools that have not fulfilled the requirements on each variable such as the Jamban Facility provide a Public Hand Washing Place, a Water Tub in a clean toilet / KM and a Bathroom cleaning tool, then the Waste Disposal Facility is placed in a safe and clean place and the TPS is far from the school environment, and waste water disposal facilities are made in a closed and water-resistant system and the Physical Quality Facilities of the building are expected to be a maximum of 28-32 people / class so that the class is not too dense.

Keywords: Elementary School Sanitation

\section{PENDAHULUAN}

Tempat-tempat umum memiliki potensi sebagai tempat terjadinya penularan penyakit. Pencemaran lingkungan, atau pun gangguan kesehatan lainya. Pengawasan atau pemeriksaan sanitasi terhadap tempat-tempat umum dilakukan untuk mewujudkan lingkungan tempattempat umum yang bersih guna melindungi kesehatan masyarakat dari kemungkinan penularan penyakit dan gangguan kesehatan lainya. Tempat atau sarana layanan umum yang wajib menyelenggarakan sanitasi lingkungan antara lain, tempat umum atau sarana umum yang di kelola secara komersial, tempat yang memfasilitasi terjadinya penularan penyakit, atau tempat layanan umum yang intensitas jumlah dan waktu kunjungannya tinggi (Budiman Chandra, 2007). Salah satu tempat umum yang harus memiliki sanitasi lingkungan yang bersih dan sehat adalah sekolah. Dimana tujuan dari sanitasi ini adalah untuk meningkatkan kualitas lingkungan yang optimal pada tempat-tempat umum terutama Sekolah, sehingga dapat melindungi masyarakat sekolah dari penularan penyakit.

Berdasarkan Peraturan Menteri Pendidikan Nasional Republik Indonesia Nomor 57 Tahun 2009 Tentang Pemberian Bantuan Pengembangan Sekolah Sehat, Sekolah Sehat adalah sekolah yang bersih, hijau, rindang, aman, dan nyaman, peserta didiknya sehat, aktif dan bugar serta berperilaku hidup bersih dan sehat.

Berdasarkan Keputusan Menteri Kesehatan Republik Indonesia Nomor 288/Menkes/SK/III/2003 Tentang Pedoman Penyehatan Sarana Dan Bangunan umum, bahwa penyelenggaraan sarana dan bangunan umum berada di luar kewenangan Departemen 
Kesehatan, namun sarana dan bangunan umum tersebut harus memenuhi persyaratan kesehatan. Hal ini telah diamanatkan pada UU No.23 Tahun 1992 tentang kesehatan pasal 22 ayat 4, bahwa setiap tempat atau sarana pelayanan umum wajib memelihara dan meningkatkan lingkungan yang sehat sesuai dengan standar dan persyaratan.

Kesehatan lingkungan sekolah bertujuan untuk meningkatkan, mewujudkan derajat kesehatan dan pengembangan siswa secara optimal. Dengan demikian, untuk mencapai kesehatan siswa secara optimal dapat dilakukan melalui program UKS, diantaranya: 1) Lingkungan kehidupan sekolah yang sehat (health school living), 2) Pendidikan kesehatan (health education), 3) Usaha pemeliharaan kesehatan di sekolah (health service in school). Program ini harus dilakukan secara terpadu dan berkesinambungan dengan tujuan untuk meningkatkan kehidupan lingkungan sekolah yang sehat dan bersih.

Dina Andriani dkk, (2013) menjelaskan bahwa untuk membiasakan hidup sehat di lingkungan sekolah mencakup beberapa hal, yaitu penyediaan air bersih, harus ada tempat pembuangan sampah dan pengelolaannya serta tersedianya pembuangan kotoran manusia atau WC di lingkungan sekolah yang memadai, dan ini semua merupakan fasilitas sanitasi lingkungan khususnya lingkungan sekolah. Dijelaskan bahwa beberapa hal yang mempengaruhi kesehatan lingkungan sekolah adalah sanitasi yang terdiri dari penyediaan air bersih, pengelolaan sampah, tersedianya pembuangan kotoran manusia (WC)/jamban yang memadai dan saluran pembungan air limbah.

Salah satu dampak yang diakibatkan dari ketiadaan akses terhadap sanitasi yang baik serta perilaku hidup bersih dan sehat adalah timbulnya penyakit, seperti diare dan kecacingan pada anak-anak, sehingga anak-anak tidak dapat berpatisipasi di sekolah. Salah satu cara untuk menangani permasalahan tersebut adalah dengan program perbaikan kondisi air minum, sanitasi serta perilaku hidup bersih dan sehat bagi siswa maupun perangkat sekolah (Anonim, 2009)

Kesehatan merupakan factor penting untuk memelihara kualitas anak, dengan anak yang sehat maka anak akan memiliki kesempatan mendapatkan pendidikan yang lebih baik juga. Anak usia 5-14 tahun yang menderita sakit sekitar 23,8\% dimana 60\% dari angka tersebut menderita sakit cukup parah dimana bisa mengganggu aktivitas sekolah dan lainnya ( Susenas BPS, 2007)

Menurut hasil penelitian Ineke Feryasari menunjukkan pemeliharaan sanitasi sekolah adalah sebagai berikut; $77.08 \%$ sekolah telah memelihara sumber air bersih, $66.67 \%$ sekolah 
telah memelihara jamban, 78.75\% sekolah telah memelihara Saluran Pembuangan Air Limbah (SPAL), 76.04\% sekolah telah memelihara sarana pembuangan sampah, dan $56.25 \%$ sekolah telah memelihara tempat cuci tangan. Hasil penelitian yang kedua menunjukkan kondisi sanitasi sekolah adalah sebagai berikut; $96.88 \%$ sumber air bersih telah memenuhi standar kesehatan, $76.27 \%$ jamban dalam kondisi bersih, aman, dan dilengkapi sarana jamban, 85.80\% Saluran Pembuangan Air Limbah (SPAL) sesuai dengan standar kesehatan,80.00\% kondisi sarana pembuangan sampah sesuai standar kesehatan, dan hanya $47.96 \%$ tempat cuci yang kondisinya telah memenuhi standar kesehatan.

Menurut hasil penelitian Dina Andriani dkk, Kondisi fasilitas pasokan air di lingkungan Sekolah Dasar Sungai Beremas Kabupaten buruknya kondisi pasokan airFasilitas dengan memasukkan persentase 31,82\%, kondisi pembuangan sampahFasilitas di lingkungan Sekolah Dasar di Sungai Beremas Kabupatentermasuk baik persentase fasilitas pembuangan kondisi limbah dari 68,18\%, kondisi fasilitas atau toilet pembuangan limbah manusia di lingkunganSekolah Dasar Sungai Beremas Kabupaten termasuk kedua persentasekondisi sarana pembuangan limbah manusia dengan 65,91\%, dan sanitasi yangkondisi makanan dan minuman sekolah dasar negeri di Kabupaten Sungai Beremastermasuk juga dengan persentase kondisi sanitasi makanan dan minuman di76,14\%

Kondisi sanitasi sekolah juga turut memperburuk derajat kesehatan anak didik, sanitasi lingkungan sekolah, seperti kondisi bangunan kamar mandi dan WC sekolah tidak terpelihara, sehingga menimbulkan pencemaran atau kontaminasi terhadap siswa yang menjalani proses belajar mengajar disekolah. Di samping itu perilaku membuang sampah sembarangan juga mengakibatkan kebersihan lingkungan sekolah tidak terpelihara (Depkes, 1993).

Sanitasi lingkungan sekolah sebagai bagian dari prasarana pendidikan cenderung dilupakan keberadaannya. Padahal kondisi sanitasi yang buruk dapat memberi pengaruh negatif terhadap tingkat kesehatan peserta didik sekolah yang bersangkutan. Unicef Indonesia dalam Ringkasan Kajian Air Bersih, Sanitasi, dan Kebersihan mengatakan bahwa sanitasi dan perilaku kebersihan yang buruk serta air minum yang tidak aman berkontribusi terhadap $88 \%$ kematian anak akibat diare di seluruh dunia. Penyakit diare sendiri menjadi penyebab utama kematian anak berusia di bawah lima tahun di Indonesia. Lebih lanjut dikatakan bahwa mencuci tangan secara tepat dapat mengurangi resiko penyakit diare sebesar 42 sampai $47 \%$. Selain dapat menyebabkan penyakit diare, sanitasi yang tidak memadai, praktek kebersihan yang buruk, serta air yang terkontaminasi dapat menyebabkan penyakit lain yang meliputi 
disentri, kolera, tipus, hepatitis, leptospirosis, malaria, demam berdarah, kudis, penyakit pernapasan kronis dan infeksi parasit usus.

Pada survei awal penelitian, peneliti melihat masih banyaknya sanitasi sekolah yang masih belum memenuhi persyaratan dan ada beberapa sekolah yang sudah memenuhi syarat salah satunya adalah Bharlind School dimana Halaman, Kualitas fisik bangunan, jamban, tempat pembuangan sampah dan air bersih sudah memenuhi syarat tetapi masih belum secara optimal. Sedangkan dibeberapa sekolah lainya peneliti masih menjumpai beberapa jamban, halaman, kualitas fisik bangunan, fasilitas pembungan sampah dan air bersih yang masih sangat tidak memenuhi persyaratan salah satunya yaitu Sekolah SDN 066428 dan SD Swasta Puteri Sion dan masih terdapat bekas-bekas buangan BAB serta sanitasi air bersihnya masih belum memenuhi persyaratan.

Berdasarkan permasalahan diatas, penulis tertarik untuk melakukan penelitian yang berjudul "Analisis Sanitasi Sekolah Dasar Negeri Dan Swasta Di Kecamatan Medan Tuntungan"

\section{METODE PENELITIAN}

Jenis penelitian yang dilakukan adalah survei yang bersifat deskriptif. Penelitian ini menggunakan sampel jenuh yaitu semua anggota populasi di gunakan sebagai sampel yaitu 10 sekolah. Untuk mengklasifikasikan nama-nama sekolah ini diberi kode dengan SDN1, SDN2, SDN-3, SDN-4 dan SDN-5.Sedangkan untuk sekolah swasta diberi kode SDS-1, SDS-2, SDS-3, SDS-4, SDS-5. Insrumen yang digunakan dalam penelitian ini adalah observasi atau pengamatan menggunakan check list. Analisis di lakukan dengan persyaratan yang berlaku sehingga disajikan dalam bentuk tabel distribusi.

\section{HASIL DAN PEMBAHASAN}

Tabel 1. Distribusi Hasil Penilaian Sarana Penyediaan Air Bersih

\begin{tabular}{lcccc}
\hline No & Sekolah & $\begin{array}{c}\text { Total Pencapaian } \\
\text { Skor }\end{array}$ & $\begin{array}{c}\text { Standard } \\
\text { Kepmenkes }\end{array}$ & Kriteria \\
\hline 1 & SDN-1 & 325 & $349-500$ & TidakSehat \\
2 & SDN-2 & 425 & $349-500$ & Sehat \\
3 & SDN-3 & 425 & $349-500$ & Sehat \\
4 & SDS-1 & 425 & $349-500$ & Sehat \\
5 & SDS-2 & 475 & $349-500$ & Sehat
\end{tabular}




\begin{tabular}{ccccc}
6 & SDN-4 & 425 & $349-500$ & Sehat \\
7 & SDS-3 & 375 & $349-500$ & Sehat \\
8 & SDN-5 & 375 & $349-500$ & Sehat \\
9 & SDS-4 & 425 & $349-500$ & Sehat \\
10 & SDS-5 & 225 & $349-500$ & TidakSehat \\
\hline
\end{tabular}

Berdasarkan tabel diatas dapat di ketahui bahwa hasil penilaian Sarana Penyediaan Air Bersih menurut Keputusan Menteri Kesehatan Republik Indonesia Nomor 1429/MENKES/SK/XII/2006 yang terdiri dari 2 kategori adalah Sehat dan Tidak Sehat, maka yang memenuhi Kriteria Sehat adalah SDN-2, SDN-3, SDS-1, SDS-2, SDN-4, SDS-3, SDN5, SDS-4dan yang Tidak Sehat adalah SDN-1, dan SDS-5.

Tabel 2. Distribusi Hasil Penilaian Sarana Jamban/Toilet

\begin{tabular}{ccccc}
\hline No & Sekolah & $\begin{array}{c}\text { Total Pencapaian } \\
\text { Skor }\end{array}$ & $\begin{array}{c}\text { Standart } \\
\text { Kepmenkes }\end{array}$ & Kriteria \\
\hline 1 & SDN-1 & 215 & $346-500$ & Tidak Sehat \\
2 & SDN-2 & 250 & $346-500$ & Tidak Sehat \\
3 & SDN-3 & 275 & $346-500$ & Tidak Sehat \\
4 & SDS-1 & 225 & $346-500$ & Tidak Sehat \\
5 & SDS-2 & 275 & $346-500$ & Tidak Sehat \\
6 & SDN-4 & 340 & $346-500$ & Tidak Sehat \\
7 & SDS-3 & 250 & $346-500$ & Tidak Sehat \\
8 & SDN-5 & 225 & $346-500$ & Tidak Sehat \\
9 & SDS-4 & 275 & $346-500$ & Tidak Sehat \\
10 & SDS-5 & 125 & $346-500$ & Tidak Sehat \\
\hline
\end{tabular}

Berdasarkan tabel diatas dapat diketahui bahwa hasil penilaian Sarana Jamban/Toilet menurut Keputusan Menteri Kesehatan Republik Indonesia Nomor 1429/MENKES/SK/XII/2006 yang terdiri dari 2 kategori adalah Sehat dan Tidak Sehat, yang memenuhi Kriteria Sehat adalah Tidak Ada dan yang Tidak Sehat adalah seluruh sekolah baik SDN maupun SDS.

Berdasarkan tabel dibawah dapat di ketahui bahwa hasil penilaian Sarana Pembuangan Sampah menurut Keputusan Menteri Kesehatan Republik Indonesia Nomor 1429/MENKES/SK/XII/2006 yang terdiri dari 2 kategori adalah Sehat dan Tidak Sehat, yang memenuhi Kriteria Sehat adalah 4 sekolah, kemudian 6 sekolahdikatagorikantidaksehat. 
Tabel 3. Distribusi Hasil Penilaian Sarana Pembuangan Sampah

\begin{tabular}{clccc}
\hline No & Sekolah & $\begin{array}{c}\text { Total Pencapaian } \\
\text { Skor }\end{array}$ & $\begin{array}{c}\text { Standart } \\
\text { Kepmenkes }\end{array}$ & Kriteria \\
\hline 1 & SDN-1 & 175 & $314-500$ & Tidak Sehat \\
2 & SDN-2 & 275 & $314-500$ & Tidak Sehat \\
3 & SDN-3 & 225 & $314-500$ & Tidak Sehat \\
4 & SDS-1 & 350 & $314-500$ & Sehat \\
5 & SDS-2 & 450 & $314-500$ & Sehat \\
6 & SDN-4 & 375 & $314-500$ & Sehat \\
7 & SDS-3 & 150 & $314-500$ & Tidak Sehat \\
8 & SDN-5 & 150 & $314-500$ & Tidak Sehat \\
9 & SDS-4 & 350 & $314-500$ & Sehat \\
10 & SDS-5 & 275 & $314-500$ & Tidak Sehat \\
\hline
\end{tabular}

Berdasarkan tabel dibawah dapat diketahui bahwa hasil penilaian Sarana Pembuangan Air Limbah menurut Keputusan Menteri Kesehatan Republik Indonesia Nomor 1429/MENKES/SK/XII/2006 yang terdiri dari 2 kategori adalah Sehat dan Tidak Sehat, yang memenuhi Kriteria Sehat adalah 6 sekolahtidaksehat, dan 4 sekolahsehat.

Tabel 4. Distribusi Hasil Penilaian Sarana Pembuangan Air Limbah

\begin{tabular}{ccccc}
\hline No & Sekolah & $\begin{array}{c}\text { Total } \\
\text { Pencapaian } \\
\text { Skor }\end{array}$ & $\begin{array}{c}\text { Standart } \\
\text { Kepmenkes }\end{array}$ & Kriteria \\
\hline 1 & SDN-1 & 225 & $251-400$ & Tidak Sehat \\
2 & SDN-2 & 325 & $251-400$ & Tidak Sehat \\
3 & SDN-3 & 250 & $251-400$ & Tidak Sehat \\
4 & SDS-1 & 325 & $251-400$ & Sehat \\
5 & SDS-2 & 375 & $251-400$ & Sehat \\
6 & SDN-4 & 250 & $251-400$ & Tidak Sehat \\
7 & SDS-3 & 200 & $251-400$ & Tidak Sehat \\
8 & SDN-5 & 250 & $251-400$ & Tidak Sehat \\
9 & SDS-4 & 375 & $251-400$ & Sehat \\
10 & SDS-5 & 250 & $251-400$ & Tidak Sehat \\
\hline
\end{tabular}

Berdasarkan tabel dibawah dapat diketahui bahwa hasil penilaian Kualitas Fisik Bangunan menurut Keputusan Menteri Kesehatan Republik Indonesia Nomor 1429/MENKES/SK/XII/2006 yang terdiri dari 2 kategori adalah Sehat dan Tidak Sehat, yang memenuhi Kriteria Sehat adalah 3 sekolahsedangkan yang yidaksehatada 7 sekolah.

Berdasarkan tabel dibawah dapat diketahui bahwa hasil penilaian Sarana Halaman Sekolah menurut Keputusan Menteri Kesehatan Republik Indonesia Nomor 
1429/MENKES/SK/XII/2006 yang terdiri dari 2 kategori adalah Sehat dan Tidak Sehat, yang memenuhi Kriteria Sehat adalah 5 sekolahdantidaksehatadalah 5 sekolah.

Tabel 5. Distribusi Hasil Penilaian Kualitas Fisik Bangunan

\begin{tabular}{ccccc}
\hline No & Sekolah & $\begin{array}{c}\text { Total Pencapaian } \\
\text { Skor }\end{array}$ & $\begin{array}{c}\text { Standart } \\
\text { Kepmenkes }\end{array}$ & Kriteria \\
\hline 1 & SDN-1 & 200 & $136-200$ & Sehat \\
2 & SDN-2 & 150 & $136-200$ & Sehat \\
3 & SDN-3 & 75 & $136-200$ & Tidak Sehat \\
4 & SDS-1 & 75 & $136-200$ & Tidak Sehat \\
5 & SDS-2 & 75 & $136-200$ & Tidak Sehat \\
6 & SDN-4 & 75 & $136-200$ & Tidak Sehat \\
7 & SDS-3 & 150 & $136-200$ & Sehat \\
8 & SDN-5 & 150 & $136-200$ & Sehat \\
9 & SDS-4 & 150 & $136-200$ & Sehat \\
10 & SDS-5 & 125 & $136-200$ & Tidak Sehat \\
\hline
\end{tabular}

Berdasarkan tabel dibawah dapat diketahui bahwa hasil penilaian Sarana Halaman Sekolah menurut Keputusan Menteri Kesehatan Republik Indonesia Nomor 1429/MENKES/SK/XII/2006 yang terdiri dari 2 kategori adalah Sehat dan Tidak Sehat, yang memenuhi Kriteria Sehat adalah 6 sekolah dan tidak sehat adalah 4 sekolah

Tabel 6. Distribusi Hasil Penilaian Halaman Sekolah.

\begin{tabular}{clccc}
\hline No & Sekolah & $\begin{array}{c}\text { Total Pencapaian } \\
\text { Skor }\end{array}$ & $\begin{array}{c}\text { Standart } \\
\text { Kepmenkes }\end{array}$ & Kriteria \\
\hline 1 & SDN-1 & 150 & $329-500$ & TidakSehat \\
2 & SDN-2 & 385 & $329-500$ & Sehat \\
3 & SDN-3 & 350 & $329-500$ & Sehat \\
4 & SDS-1 & 475 & $329-500$ & Sehat \\
5 & SDS-2 & 495 & $329-500$ & Sehat \\
6 & SDN-4 & 450 & $329-500$ & Sehat \\
7 & SDS-3 & 225 & $329-500$ & TidakSehat \\
8 & SDN-5 & 300 & $329-500$ & TidakSehat \\
9 & SDS-4 & 425 & $329-500$ & Sehat \\
10 & SDS-5 & 250 & $329-500$ & TidakSehat \\
\hline
\end{tabular}

\section{KESIMPULAN}

Berdasarkan hasil observasi dan pembahasan yang telah dijabarkan maka dapat disimpulkan sebagai berikut: 
1. Pada variabel Sarana Penyediaan Air Bersih di SD Negeri dan Swasta yang termasuk kategori Sehat adalah SDN 067247, SDN 065015, SDS Bharlind School, SD Katolik Budi Murni-2, SDN 068003, SDS Muhamadiyah 34, SDN 068344, dan SDS Elida.

2. PadaVariabel Sarana Fasilitas Jamban/Toilet di SD Negeri dan Swasta yang termasuk kategori Sehat adalah Tidak ada, hal ini disebabkan karena hasil observasi pada hasil penelitian seluruh Sekolah Negeri dan Swasta mendapatkan nilai di bawah 346-500.

3. Pada variable Sarana Pembuangan Sampah di SD Negeri dan Swasta yang termasuk kategori Sehat adalah SDS Bharlind School, SD Katolik Budi Murni-2, SDN 068003 dan SDS Elida.

4. PadaVariabel Sarana Pembuangan Air Limbah (SPAL) di SD Negeri dan Swasta yang termasuk kategori Sehat adalah SDS Bharlind School, SD Katolik Budi Murni-2 dan SDS Elida.

5. PadaVariabel Sarana Kualitas Fisik Bangunan di SD Negeri dan Swasta yang termasuk kategori Sehat adalah SDN 066428, SDN 067247, SDS Muhamadiyah 34, SDN 068344, SDS Elida dan SDS Puteri Sion.

6. PadaVariabel Sanitasi Halaman Sekolah di SD Negeri dan Swasta yang termasuk kategori Sehat adalah SDN 067247, SDN 065015, SDS Bharlind School, SD Katolik Budi Murni2, SDN 068003, SDN 068344 dan SDS Elida.

\section{SARAN}

Bagi Peneliti Diharapkan dapat dijadikan sebagai bahan bacaan sekaligus sebagai informasi untuk melakukan penelitian yang lebih detail tentang Sanitasi SDN dan SDS di Kecamatan Medan Tuntungan. Bagi Kepala Dinkes Khususnya bagian pengawasan Sekolah Dasar hendaknya di sediakan sarana dan prasarana Sanitasi Sekolah Dasar Khususnya Tempat Sampah, serta fasilitas jamban agar proses belajar mengajar dapat berjalan dengan baik. Bagi Kepala Sekolah.Hendaknya perlu di perhatikan kebersihan sarana dan prasarana sekolah agar dilakukan pembersihan secara rutin dan dipertimbangkan untuk lebih sering mengadakan kegiatan seminar atau pun buku-buku bacaan, artikel serta jurnal tentang Sanitasi Sekolah Dasar.

Bagi Pelayan Kesehatan Harapkan Perlu dilakukan penyuluhan secara rutin tentang Sanitasi Sekolah Dasar khususnya kepada siswa agar lebih mengutamakan Kebersihan perorangan sehingga tidak mudah terserang oleh penyakit. Bagi Peneliti Selanjutnya 
Diharapkan dimasa yang akan datang dapat digunakan sebagai salah satu sumber data untuk penelitian selanjutnya dan dilakukan penelitian lanjut berdasarkan faktor lainya variabel yang berbeda, jumlah sampel yang lebih banyak, tempat dan desain yang lebih tepat dan tetap berhubungan dengan Sanitasi SDN dan SDS.

\section{DAFTAR PUSTAKA}

Chandra. (2007) PengantarKesehatanLingkungan. Jakarta. Kedokteran, EGC.

Waluya, B. (2009) PengelolaanLingkunganHidup TK-SMA (pp 45-61) Jakarta. Direktori File UPI

.(2006). Keputusan Menteri Kesehatan RI No 1429/MENKES/SK/XII/2006: Tentang Pedoman Penyelenggaraan Kesehatan Lingkungan Sekolah. Jakarta: Departemen Kesehatan.

Presiden RI. (2006). Undang-Undang No. 23 Tentang Kesehatan. Jakarta: Departemen Kesehatan [Online]. Dari: http://hukum.unsrat.ac.id/uu/uu_23_92.htm [Diakses: 5 Desember 2016].

Notoatmodjo, S. (2003). Ilmu Kesehatan Masyarakat Prinsip-Prinsip Dasar. Jakarta: PT. Rineka Cipta.

Kusnoputranto, H. (2000). Kesehatan Lingkungan. Jakarta: Departemen P dan K FKM UI.

Azwar. (2010). Pengantar Ilmu Kesehatan Lingkungan. Jakarta: PT. Mutiara Sumber Widya Offset.

Sumantri, A. (2010). Kesehatan Lingkungan. Jakarta: Kencana Prenada Media Group.

Ineke Feryasari. 2010. Pemeliharaan Sanitasi Di Sekolah Dasar Negeri Se-Kecamatan Jetis Kabupaten Bantul, FKM-Universitas Negeri Yogyakarta.

Puspantoro, B. (2010). Kontruksi Bangunan Tidak Bertingkat. Yogyakarta: UAJY.

Eka Irdianty. 2011. Studi Deskriptif Sanitasi Dasar di Tempat Pelelangan Ikan Lempasing Teluk Betung Bandar Lampung. UI.

Budiman, S. \&. (2010). Ilmu Kesehatan Masyarakat Dalam Konteks Kesehatan Lingkungan. Jakarta: Buku Kedokteran EGC

Gurit Mustika Sari. 2011. Gambaran Sanitasi Sekolah Dasar Negeri Dan Swasta Mandrasah Ibtidaiyah di kecamatan jelbuk kabupaten Jember . Universitas Jember.

Santoso, I. (2015). Sanitasi Sekolah. In I. Santoso, Inspeksi Sanitasi Tempat-Tempat Umum (pp. 77-80). Yogyakarta: Gosyen publising.

Candra, B. (2007). Pengantar Kesehatan Lingkungan. Jakarta: Buku Kedokteran EGC.

Trahati, M. R. (2015). Implementasi Pendidikan Karakter Peduli Lingkungan Di Sekolah Dasar Negeri Tritih Wetan 05 Jeruklegi Cilacap. Jurnalkarakter peduli lingkungan hal 5. 
Dina Andriani, Slamet Rianto, \& Aslan Sari Thesiwati. (2013). Studi Tentang Sanitasi Lingkungan Sekolah Dasar Negeri DiKecamatan Sungai Beremas Kabupaten Pasaman Barat. jurnal sanitasi sekolah, hal 1-2.

Wijayanti, I. P. (2013). Studi Fisik Dan Sanitasi Sekolah Dasar Negeri Di Wilayah Surabaya Utara Dan Surabaya Barat. Junal Studi Fisik dan Sanitasi Sekolah Dasar , 42-43. 